\title{
O estatuto político da amizade: A alma do osso, de Cao Guimarães
}

\author{
Rafael de Almeida
}

Resumo: A partir do conceito de amizade proposto por Giorgio Agamben, este ensaio reflete, em uma interface entre estética e política, acerca das relações de poder presentes em $A$ alma do osso (Cao Guimarães, 2004). O maior relevo é dado ao modo pelo qual o cineasta partilha, por meio do filme, sua existência com o ermitão Dominguinhos da Pedra, bem como as reverberações que isso garante à forma do documentário.

Palavras-chave: documentário; amizade, $A$ alma do osso (filme)

Abstract: The political statute of friendship: The Soul of the Bone, by Cao Guimarães - Starting from the concept of friendship proposed by Giorgio Agamben, this essay, at the interface between aesthetics and politics, ponders upon power relations in the documentary The Soul of the Bone (Cao Guimarães, 2004). The greatest emphasis focuses on how, through this film, the filmmaker shares his existence with the hermit Dominguinhos da Pedra, as well as the reverberations that this ensures in shaping the documentary.

Keywords: documentary; friendship; The Soul of the Bone (film)

O cinema como a ferramenta e o lugar de uma relação possível, real, entre nós.

Jean-Louis Comolli

O artista é criador de verdade, pois a verdade não tem de ser alcançada, encontrada nem reproduzida, ela deve ser criada. 


\section{O estatuto político da amizade}

Na esteira de Aristóteles, Agamben nos lembra que a "amizade é a instância desse com-sentimento da existência do amigo no sentimento da existência própria" (AGAMBEN, 2009, p. 89). De acordo com o autor, a amizade seria uma espécie de des-subjetivação no cerne da sensação mais pessoal de si, já que não se trata de compreender o amigo como um outro eu, mas um outro do mesmo. Isto é, a percepção dos processos de subjetivação da minha existência seriam com-sentidos pelo amigo, esse outro de mim mesmo que seria perpassado pela sensação que experimento.

Dessa maneira, o que há para ser dividido, repartido, compartilhado, no contexto da amizade, vai além de algo em si: passa a ser a própria existência, a vida, divisão que antecede qualquer outra. Trata-se, então, muito menos de com-dividir gostos, afinidades, semelhanças, lugares, trajetórias comuns do que o ser, o fato de existir por si, em toda sua fragilidade e beleza.

Partindo desse pressuposto, acredito que vemos surgir em A alma do osso (Cao Guimarães, 2004) uma relação de amizade entre o diretor e o personagem real Dominguinhos da Pedra. O documentário revela a existência aparentemente isolada de um ermitão, de 72 anos, que vive em uma caverna no interior de Minas Gerais. Aliás, menos do que revelar, ele se torna um instrumento de partilha dessa existência. O processo de realização do filme serve como mediador para a instauração desse afeto.

Uma série de acontecimentos, factuais, no entanto encravados na vida dos envolvidos, nos leva a crer nisso: a recusa de Dominguinhos a receber um pagamento por sua participação no filme, apesar da insistência de Cao; os presentes oferecidos pelo diretor que, com resistência, são aceitos; o interesse de "comprar os presentes", em vez de simplesmente recebê-los, por parte do protagonista; a confiança mútua entre eles sentida, se não consentida, pelo espectador durante a projeção; e, por fim, a promessa dos "bens" de Dominguinhos a Cao, quando o velho morresse.

Tudo isso nos remete ao viés político impregnado na noção de amizade proposta por Agamben, pois a existência, enquanto ela mesma e sensação, é já continuamente dividida. "E é essa partilha sem objeto, esse com-sentir originário que constitui a política" (AGAMBEN, 2009, p. 92). No âmbito da relação documentária que nos propomos a investigar, entendemos que compartilhar denota que os personagens, e aqui consideramos os dois polos dessa amizade, com-divisão do ser - o que filma e o que é filmado -, "estão lá inteiramente e sem reservas, que dão o que têm e o que não têm, que dão o que sabem que têm e o que sabem que não têm, tanto quanto o que não sabem que têm e o que não sabem que não têm" (COMOLLI, 2008, p. 155).

Penso ser nesse sentido que Cao Guimarães afirma que um "personagem de documentário entrega sua vida para ser retratada na medida de sua confiança por quem a está retratando. Não existem fórmulas, não existem regras. Tudo passa muito mais por talvez 
uma ternura do olhar do que por um bloco de notas". E "esta entrega, esta confiança, esta afetividade se propaga até a montagem e finalização do filme" ${ }^{1}$ Ou seja, é refletida na própria forma do filme, em sua superfície.

\section{Outrem como estrutura}

Se existe essa relação nascente de amizade entre o diretor e o personagem, ela não poderia surgir da forma em que comumente é abordada a representação do outro no cinema documentário, na qual há uma divisão clara entre sujeito e objeto. Trata-se menos da figura de um eu diante da alteridade do que da "expressão de um mundo possível" a partir de "outrem como estrutura". A partir de Deleuze, creio que a consequência básica da presença dessa estrutura, em detrimento do modelo dualista usual, é gerar uma diferença entre a consciência do documentarista e seu objeto. O diretor instaura no mundo, junto ao seu personagem, um "mundo de possibilidades, de fundos, de franjas, de transições" (DELEUZE, 2007b, p. 317-319), traçando, assim, um plano de imanência que guarda um conjunto de variabilidades, de mundos possíveis.

Sendo assim, podemos dizer que, quando Cao alcança a realidade exposta por Dominguinhos, não faz nada além de explanar, cultivar e realizar o mundo possível do personagem. O diretor atualiza um mundo virtual possível. E, se é verdade que outrem já oferece certa realidade aos possíveis que abarca através da fala, Cao sustentará ao máximo o silêncio de Dominguinhos durante a narrativa, potencializando a falsidade dessa ausência de palavras. Retornaremos a isso mais adiante. Nesse sentido, a "aparição de um outro, com traços particulares e individualizados, emerge, portanto, da estrutura outrem" (GUIMARÃES, 2010, p. 191).

Aqui, é bom lembrar, não falo de uma relação entre sujeitos, intersubjetiva, mas do próprio ser dividido pela esfera política da amizade. O nosso amigo-documentarista estabelece uma ligação com o outro, por meio de seu "não eu", do "entre-dois" do outro e dele próprio. Pois é preciso passar pelo outro para que a representação, enquanto imagem, surja. Essa imagem como terceiro, como constituinte da relação com o outro, sendo simultaneamente semelhante e diferente do documentarista (COMOLLI, 2008, p. 99). O que Cao não é e, no entanto, o constitui diante de Dominguinhos?

É na busca pela resposta desse questionamento que outrem (como estrutura) atua. "Outrem é um estranho desvio, ele baixa meus desejos sobre os objetos, meus amores sobre os mundos", diz Deleuze (2007b, p. 317-319). É embasado por esses afetos que Cao Guimarães se lança e imerge no lago (realidade) do mundo possível do ermitão. Imersão a partir da qual percebemos a amizade entre eles. Amizade essa que, no entanto, guarda as diferenças dos indivíduos, formas de vida, envolvidos.

1 Cao Guimarães em entrevista concedida à revista Época, em abril de 2004. 
Em Breve nota sobre o eremita, Cao nos dá a ver um pouco do quanto, apesar do compartilhar da existência e do reconhecimento de parte de si no outro, ambos mantinham práticas cotidianas distintas. "Armamos uma barraca ao lado de sua gruta e passamos alguns dias convivendo com ele. Para o nosso pequeno fogão a gás ele tinha um fogãozinho na pedra movido a graveto, lenha e fogo." Então, passa a enumerar as incontáveis diferenças que os singularizavam (ato de individuação) - "Para os nossos cantis de água, recipientes de plástico, garrafas velhas de refrigerante cortadas ao meio e devidamente tampadas para proteger a água dos ratos e das baratas" -, embora estivessem partilhando o próprio fato de ser (processo de des-subjetivação). "Para as nossas modernas lanternas de luz halógena, a luz das estrelas, do fogo e a rápida dilatação das pupilas na escuridão. Para o nosso café coado, café com borra." E segue listando dessa forma até abandonar o que os diferencia pelo que possuem - "Para a nossa ansiedade em satisfazer o estômago que entorpece o cérebro e o corpo, a alimentação pela palavra e a voracidade do pensamento de estômago vazio interrompido de quando em vez por mordidas em bananas ou o que estiver disponível" - para o que os compõem, enquanto corpos, matéria. "Para a nossa dificuldade em dobrar as pernas, sentar de cócoras, deitar no chão duro, agachar, levantar, dobrar, esticar o corpo, o balé natural de um homem-mola, homem-elástico, homem-osso-veia-carne na medida do necessário" (GUIMARÃES, 2009, p. 1).

Essa alteração da ordem do que promove a individuação no texto de Cao talvez seja indicativa da maneira como o cineasta percebe o próprio cinema do real: arte do encontro, "um encontro com o que você imagina e, no entanto revela-se de outra forma. Nessa revelação, nesse susto, somos convocados diante de um espelho que mostra outro rosto", declara Cao (GUIMARÃES, 2007, p. 69). Revela o rosto daquele que é o "não eu", sem ser o outro. Ou seja, Cao não era um outro Dominguinhos, e vice-versa, por mais que o cineasta estivesse tomado por um "devir-outro".

É apoiado na estrutura de outrem que percebo $A$ alma do osso, enquanto processo de feitura, como um ato de amor, e "como qualquer relação amorosa que se preze gera uma ética particular, recíproca, de entrega e cuidado", ${ }^{2}$ lembra o diretor. Nesse sentido, acrescenta Comolli: "Não se filma sem amor, sem desejo, sem inconsciente, sem corpo; mas também não se filma sem consciência, sem moral, sem cálculo, sem gostos e desgostos. Questão de corpo" (COMOLLI, 2008, p. 129). O que nos leva a inferir que embora compreendamos, nesse caso, filmar como um ato de amor, de desejo, essa prática não está livre de sua dimensão de poder. E, ainda, estamos tratando de amizade. Dupla dimensão política.

\section{Poder e resistência}

Comolli, enquanto teórico, cineasta e professor, confessa que, no fim das contas, o que ele tinha a ensinar poderia ser resumido em algo de extrema simplicidade: "investir

2 Cao Guimarães em entrevista concedida à revista Época, em abril de 2004. 
a si mesmo", isto é, "engajar-se realmente, de corpo e alma, na relação documentária". Ou ainda: "estar presente e durar". Segundo ele, essa "é a condição de uma consciência de que não se filma impunemente". Se "filmar mobiliza poder" e instaura "relações de força", a questão que fica é: "como fazer com o corpo do outro, ou melhor: com o outro como corpo" (COMOLLI, 2008, p. 339). ${ }^{3}$ Direcionando esse questionamento para a discussão que aqui temos proposto: como considerar as relações de poder entre aquele que filma e o que é filmado, se a amizade já os leva a partilhar a existência, a própria vida? Circunstanciemos.

Segundo Foucault, o poder "se produz a cada instante, em todos os pontos, ou meIhor, em toda relação entre um ponto e outro. O poder está em toda parte; não porque englobe tudo e sim porque provém de todos os lugares" (FOUCAULT, 1988, p. 103). Ou seja, o poder seria munido de uma espécie de onipresença. Logo, estaria presente tanto na amizade entre Cao e Dominguinhos quanto na relação que travam pela mediação da câmera. Justamente devido à onipresença, seriam inscritas nas relações de poder as resistências, como o "interlocutor irredutível". Onde há poder, há resistência. Distribuídos irregularmente, "os pontos, os nós, os focos de resistência disseminam-se com mais ou menos densidade no tempo e no espaço" e manifestam-se de diversas maneiras, às vezes "inflamando certos pontos do corpo, certos momentos da vida, certos tipos de comportamento" (FOUCAULT, 1988, p. 106). Aqui, se por um lado suspeitamos que a amizade, enquanto acontecimento, não instaure fortes variações de poder/resistência, por outro a posse da câmera e seu manuseio promove um ganho de poder para o diretor do filme. $\mathrm{O}$ poder está com quem detém a câmera. É inegável que há um exercício de poder no ato de enquadrar. Entretanto, se "onde há poder, há resistência", nos resta, neste instante, refletir acerca dos atos de resistência empenhados pelo eremita, protagonista do documentário.

O silêncio parece-me ser a primeira investida do personagem contra o poder exercido pelo diretor. Somos apresentados a Dominguinhos de maneira delicada. Antes de entrarmos em sua casa, se assim podemos chamar, nos é apresentado o seu entorno: o verde, entre matas e morros. Silente, o personagem segue seus afazeres como se nada estivesse acontecendo: recolhe pedaços de madeira, prepara o fogo e começa, da maneira que lhe é possível, a preparar uma refeição. A câmera o acompanha apenas, fingindo pautar-se por uma estética observacional, para revelar o cotidiano do eremita maltrapilho que traz as marcas do tempo em sua própria pele. Os primeiros quinze minutos do filme giram em torno da preparação desse alimento, que pelo arrastar do tempo nos permite experimentar um pouco do amargo silêncio vivido por Dominguinhos diariamente.

A impressão que temos é que o silêncio, enquanto "forma de discurso" (SONTAG, 1987, p. 18), é utilizado pelo ermitão para afrouxar os laços de poder exercidos sobre ele, bem como dar "margem a tolerâncias mais ou menos obscuras" (FOUCAULT, 1988, p. 112).

3 Citação extraída da nota 2 do texto "Potências do vazio e plenos poderes". 
Pois, se por um lado o discurso é capaz de produzir poder, por outro, o silêncio, enquanto forma discursiva, poderia também debilitá-lo, miná-lo, enfraquecê-lo. No entanto, estou enganado. Cao Guimarães alega que, na edição de $A$ alma do osso, apesar de ter pouca clareza do que seria o documentário, "queria um filme mais silencioso que tratava da vida de um eremita, não queria um filme com muita fala...".${ }^{4}$ Logo, o silêncio não constituiria nenhum tipo de resistência ao poder do que filma.

Todavia, ao contrário do esperado pelo diretor e sua equipe, Dominguinhos "só parava de falar para fazer café, dormir, tocar viola e exercer rituais bastante particulares que fomos identificando pouco a pouco", informa Cao. "O silêncio para ele parece ser já o lugar-comum, o estado normal em que o tempo passa. A fala é o estado de exceção" (GUIMARÃES, 2009, p. 1). Por volta de quarenta minutos de duração do filme, a figura silenciosa e distante do ermitão é revertida para um simpático e inimaginável senhor falante, em que o desejo por se expressar é tão forte que as palavras, por vezes, não conseguem se ordenar como deveriam. Por essa perspectiva, temos que o mais relevante ato de resistência empenhado por Dominguinhos, contrariamente ao que pensamos em um primeiro instante, é o de fala. O filmado oferece a aquele que filma o contrário do que ele desejava. E nem por isso eles deixam de com-partilhar a própria existência durante esse tempo. Nessa ocasião, o estatuto político da amizade vai além das relações de poder instauradas pela câmera.

A sensação estética de solidão, que temos ao assistir a grande parte do filme, intensificada pelo silêncio, não passou, nesse sentido, de outra artimanha do poder. O silêncio existe, na obra, apenas em um "sentido arquitetado ou não literal" (SONTAG, 1987, p. 17). O processo de montagem privilegia os momentos silenciosos das imagens captadas, garantindo a satisfação do desejo daquele que detém o poder (que mais uma vez é o que domina a máquina - ilha de edição) e potencializando o falso. Devemos tomar esse apelo ao silêncio em $A$ alma do osso menos como uma mera "rejeição hostil à linguagem" do que uma "altíssima estima pela linguagem - por seus poderes, sua força passada e os perigos correntes que coloca a uma consciência livre" (SONTAG, 1987, p. 33).

\section{O falso como potência}

Se "não existe o estar sozinho em um documentário", já que para filmar a ausência é preciso haver uma presença, o que encontramos em $A$ alma do osso é uma espécie de "performance da solidão" (EDUARDO, 2008, p. 1). Se já sabemos que Dominguinhos, além de não estar sozinho por conta da relação mediada pela câmera, compartilha uma amizade com Cao Guimarães, ele não experimenta, ao menos naquele momento, o isolamento. Se em um primeiro instante o personagem apresenta uma aparência silente, depois é revelado como o total oposto disso. Enfim, "por toda parte são as metamorfoses

4 Cao Guimarães em entrevista concedida a Cezar Migliorin, em dezembro de 2006. 
do falso que substituem a forma do verdadeiro" (DELEUZE, 2007a, p. 165), tudo corrobora para a produção da ausência: artifício do falso, compreendido pelo documentário, pela narrativa, como potência.

Essa compreensão garante à narração um novo estatuto: ela deixa de almejar à verdade para "se fazer essencialmente falsificante", conforme Deleuze. Trata-se de uma potência do falso que "substitui e destrona a forma do verdadeiro, pois ela afirma a simultaneidade de presentes incompossíveis, ou a coexistência de passados não necessariamente verdadeiros". Atentemo-nos para o fato de que outrem como estrutura já garantia a existência de mundos possíveis, na relação entre Cao e Dominguinhos. Na ordem da descrição cristalina, da imagem-tempo, a indiscernibilidade entre real e imaginário já era alcançada, "mas a narração falsificante que lhe corresponde vai um pouco adiante e coloca no presente diferenças inexplicáveis; no passado, alternativas indecidíveis entre o verdadeiro e o falso". Aqui, confirmamos que o silêncio é usado pelo diretor, além de forma de poder, como vimos, como uma potência falsificante. "O homem verídico morre, todo modelo de verdade se desmorona, em favor da nova narração" (DELEUZE, 2007a, p. 161).

O olhar imaginário de Cao Guimarães, tomado por esse "devir-outro", transmuta o real em algo imaginário, ao mesmo tempo que faz o processo inverso, ao oferecer uma sensação de realidade ao espectador. Essa é a potência do falso em A alma do osso. Não que o filme seja completamente falso, mas se apresenta libertador das categorias da percepção ao permitir ser olhado de formas diversas (inclusive com um "olhar imaginário"), ao demonstrar, pelo próprio processo de costura, que se trata de uma construção, de um jogo instaurado entre mundos possíveis. Por exibir a falsificação, ele parece mais verdadeiro.

Em um determinado momento do documentário, percebemos que talvez o eremita não esteja tão sozinho quanto pensávamos. E, em breve, estará seu Dominguinhos rodeado por estudantes que, inclusive, o fotografam, enquanto, com muita destreza - "Entendeu?", "Vai escutando!" -, ele conta histórias que só ele sabe. A noite chega, o ônibus parte, a escuridão se aproxima e traz com ela a solidão. ${ }^{5}$

No entanto, se abolimos, simultaneamente, o mundo verdadeiro e o das aparências, cabe a pergunta: o que nos resta? Responde-nos Deleuze que restam os corpos, "que são forças, nada mais que forças. Mas a força já não se reporta a um centro, tampouco enfrenta um meio ou obstáculos. Ela só enfrenta outras forças, se refere a outras forças, que ela afeta e que a afetam" (DELEUZE, 2007a, p. 170). Em nenhum instante deixamos de tratar de relações de poder. Se por um lado, Cao reserva os poderes que possui pelo domínio das máquinas, por outro o partilhar da existência fez com que em determinadas passagens sentíssemos, enquanto espectadores, um desejo de partilha desse poder, afinal eram amigos.

5 Consuelo Lins, em Tempo e dispositivo nos filmes de Cao Guimarães (Devires, Belo Horizonte, v. 4, n. 2, 2007), considera essa passagem como ilustrativa de que talvez não seja mais possível realizar uma ruptura com o "social": o ermitão, do qual testemunhamos a solidão em boa parte do filme, é também ponto turístico, segundo ela. A lógica do espetáculo constituiria o mundo, afetando mesmo existências aparentemente isoladas, e o filme em si não deixaria de fazer parte dela (mesmo que a desloque), pois transformaria o eremita em imagem e passaria, assim, a circular pelo mundo. 
Consideramos que Cao Guimarães opera, por vezes, uma retirada estética como forma de "dar" poder ao outrem, partilhá-lo. Segundo Comolli, nessas ocasiões, mais raras, "o gesto da mise-en-scène acaba por se apagar para dar lugar à automise-en-scène do personagem". Trata-se de uma "dança a dois", na qual a tentativa maior talvez fosse de experimentar ser conduzido, em vez do oposto. "A mise-en-scène mais decidida (aquela que supostamente vem do cineasta) cede lugar ao outro, favorece seu desenvolvimento, dá-lhe tempo e campo para se definir, se manifestar". Por essa perspectiva, filmar assume o papel de "uma conjugação, uma relação na qual se trata de se entrelaçar ao outro - até na forma" (COMOLLI, 2008, p. 85). Mas, se não me engano, essa retirada estética também pode ter sido dissimulada.

Digo isso pois a percebo pela superfície da tela, através de camadas subterrâneas de realidade, de formas e sentidos de espessuras variadas, por crer que, talvez, seja na superfície "que uma imagem desconhecida das coisas se determina" (DELEUZE, 2007b, p. 324). E sem desconsiderar o sentido político de superfície como "uma forma de partiIha do sensível" (RANCIÈRE, 2005, p. 21): que o filme, enquanto discurso, exerce poder sobre aquele que o assiste, sobre mim. O próprio Cao pensa que a "pele das coisas é um universo imenso que revela muito do que no fundo se esconde" (GUIMARÃES, 2007, p. 70). Concordando com ele, considero a pele de $A$ alma do osso de vasta dimensão, o que não significa dizer de pouca profundidade.

\section{A pele do filme ou o discurso pela superfície}

A instauração de outra instância narrativa confirma o caráter de preparação do primeiro bloco do filme (o preparo da refeição) para um documentário, repleto de silêncios e poesia - como o mundo do nosso personagem. Ou melhor, como o mundo possível, percebido por Cao, de seu Dominguinhos. Os pixels do vídeo dão lugar aos expressivos grãos do super-8 mm para acompanhá-lo em uma caminhada, entre galhos de árvores e pedras, em busca de água. Na beira de um riacho, ele se abaixa e recolhe um pouco em uma lata. E o olhar do documentarista, aparentemente tão fiel aos movimentos do personagem, prende-se numa bolha de ar formada pelo movimento das águas. E a segue pelo rio enquanto pode. Antes que a solidão a desfaça.

A sequência de belíssimas imagens que se segue é repleta de gotas-d'água presas em uma teia de aranha, movendo-se ao sabor do vento. Vibrando caoticamente à espera de algo que as desestabilize. Talvez a solidão pudesse ser compartilhada. Subitamente, temos imagens subaquáticas de peixes nadando. Um corpo coletivo, compartilhado, dividido. Acima dali, tudo é azul no encontro entre céu e mar. E, por fim, voltamos à bolha e, por consequência, ao eremita - sentado parece esperar pelo que está por vir.

A alma do osso nos presenteará com vários momentos como esse, em que a exploração de materiais de composição provenientes da natureza - galhos, pedras, água, 
gotas, peixes, flores, fogo etc. - possibilita a criação de metáforas visuais capazes de expressar, pela superfície da imagem, por sua materialidade, o olhar imaginário de Cao, tomado por esse "devir-outro", com-dividido, repleto de amores pelo mundo de outrem, potencializando falsidades (fissuras do real) para se passar por solitário na amizade. O ponto de vista do cineasta está presente "na linguagem, com sua manipulação de luz, textura, cor, procurando uma imagem fabular-mítica, não uma imagem de indicialidade de real" (EDUARDO, 2008, p. 1).

Isso porque as imagens eletrônicas configuram-se como "fluidas, ruidosas, escorregadias e infinitamente manipuláveis", não autorizando serem tratadas no plano do mero registro documental, da referencialidade. Pelas características que lhe são intrínsecas, essas imagens pouco se curvam a uma utilização que simplesmente homologa o "real". Adversamente, "se a 'realidade' comparece em alguma instância nessas atividades, ela se dá como decorrência de um trabalho de escritura" (MACHADO, 2007, p. 30). Por extensão, de superfície. Como diria Aumont, "trabalho plástico e trabalho semântico não se separam". Isto é, "trabalhar a aparência plástica da imagem é sempre procurar modelar o material fotográfico para torcê-lo 'no sentido do sentido'". Ao contrário, o sentido apenas é atingido, especificamente, "fora de qualquer tomada de poder indevida da palavra, do verbo, no trabalho plástico, único legítimo, único nobre" (AUMONT, 2004, p. 171).

Rancière nos dirá que é na interface entre distintos suportes, "nos laços tecidos entre o poema e sua tipografia ou ilustração, entre o teatro e seus decoradores ou grafistas, entre o objeto decorativo e o poema" e, aqui acrescentamos, entre o vídeo e o super-8 "que se forma essa 'novidade' que vai ligar o artista, que abole a figuração, ao revolucionário, inventor da vida nova" (RANCIÈRE, 2005, p. 23). Questão política.

\section{Outra superfície}

Comolli nos fala que "o cinema não filma os seres ou as coisas como tais", no entanto, "filma suas relações com o tempo - as relações dos seres e das coisas com o tempo da tomada". Nesse sentido, o filme seria capaz de tornar "sensível, perceptível e, às vezes, diretamente visível o que não se vê: a passagem do tempo nos rostos e nos corpos" (COMOLLI, 2008, p. 113). Em A alma do osso, é através do rosto de seu Dominguinhos que vemos o tempo que o perpassa, enquanto corpo, enquanto matéria. É por meio das rachaduras de seus pés, da textura de sua pele e das marcas em seu rosto que sentimos "os vestígios das passagens e das velocidades que o percorrem" (GUIMARÃES, 2010, p. 194).

Dominguinhos, como um homem, um velho, um ermitão, fala uma "língua cujos traços significantes são indexados nos traços de rostidade específicos". O que significa que, antes de ser reconhecido como indivíduo (Dominguinhos da Pedra), a sua rostidade define "zonas de frequência ou de probabilidade" (DELEUZE; GUATTARI, 1996, p. 32), como qualquer outro rosto, logo "reproduz na sua própria estrutura a dualidade de próprio 
e impróprio, de comunicação e comunicabilidade, de potência e de ato que o constitui". O rosto de Dominguinhos Ihe é próprio, porque pertence a ele, no entanto não é suficiente, em um primeiro momento, para que ele seja singularizado enquanto indivíduo; comunica, já que seus traços de rostidade são postos a serviço da significância e da subjetivação, dando abertura a mundos possíveis, porém pode otimizar o ato comunicativo maximizando a ausência de ruídos de expressão; é potência, pois se constitui por uma multiplicidade de semblantes, todavia é ato por ser. Enfim, o rosto, não só de Dominguinhos, é "formado como um fundo passivo sobre o qual brilham os traços expressivos ativos", nos diz Agamben (2000, p. 98).

O rosto apenas se produz quando ganha caráter de paisagem, quando passa por um processo de desterritorialização - deixando de ser percebido como cabeça - para ser posto a serviço da significância, por exemplo. Nessa perspectiva, se o rosto trata-se de uma desterritorialização da cabeça, a paisagem seria uma desterritorialização do mundo (DELEUZE; GUATTARI, 1996). A paisagem "não é o espaço, e sim uma qualidade do espaço", o que faz com que ela não lide "com a medida, mas com o sentimento" (AUMONT, 2004, p. 230). Acredito ser nesse sentido que Cao explora tanto o rosto de Dominguinhos, e sua pele (superfície), quanto, na mesma medida, a natureza - como material plástico, material de composição. Pois se o eremita vivia isolado na natureza, talvez por amor a ela, seria possível relacionar essas duas paisagens. Encontrar o rosto de um na paisagem do outrem, e vice-versa. ${ }^{6}$

É por esse motivo que endossamos a proposição de Deleuze e Guattari: "o close de cinema trata, antes de tudo, o rosto como uma paisagem". Pois "não há rosto que não envolva uma paisagem desconhecida, inexplorada, não há paisagem que não se povoe de um rosto amado ou sonhado, que não desenvolva um rosto por vir ou já passado" (DELEUZE; GUATTARI, 1996, p. 38). Os três belos planos iniciais de $A$ alma do osso são da paisagem que cerca a gruta do protagonista, e logo em seguida somos apresentados ao personagem e, por meio de um close, a outra paisagem: à textura de sua pele, que não deixa de ser um rosto. A rostidade de Dominguinhos evoca a paisagem à qual seu corpo se mescla, bem como a montanha evoca o rosto do nosso protagonista, o qual a teria munido com suas próprias linhas, traços e rugas.

Ao operar uma potencialização do falso o close do rosto no cinema faz, por um lado, com que ele reflita a luz, e, por outro, é responsável por acentuar-lhe as sombras até torná-lo imerso na escuridão (DELEUZE; GUATTARI, 1996, p. 32). A propriedade do rosto apenas é revelada enquanto oculta, "e oculta na mesma medida em que revela". É isso que Agamben nomeia como tragicomédia da aparência. O rosto seria "unicamente o lugar da verdade" e "imediatamente o lugar de uma simulação". Logo, o homem "não é nada mais que essa dissimulação e essa inquietude na aparência" (AGAMBEN, 2000, p. 94-95). Tendo sido o falso potencializado por forças advindas de fontes diversas, inclusive intrínsecas ao próprio rosto, não tivemos acesso, de fato, ao seu Dominguinhos.

6 Agamben dirá que "por toda parte em que algo alcança a exposição e tenta tomar o próprio ser exposto - por toda parte em que um ser aparece afundado na aparência e deve, desde o início, retornar a ela -, tem-se um rosto". E, nesse sentido, a arte poderia "dar um rosto até mesmo a um objeto inanimado, uma natureza-morta" (AGAMBEN, 2000, p. 92). 
Trazer à aparência a aparência enquanto tal é a tarefa da política, nos diria o teórico italiano. Logo, teria sido um trabalho para Cao, como amigo. No entanto, ele preferiu, sabiamente, outro caminho. Preferiu olhar Dominguinhos nos olhos e receber de volta seu olhar, exibindo o rosto, deixando que no vazio desses olhares tivessem "lugar o amor e a palavra". Se, como vimos, a superfície é uma forma de partilha do sensível, a "exposição é o lugar da política" (AGAMBEN, 2000, p. 93). Pois o rosto nada mais é do que uma superfície composta de linhas, traços, rugas etc.

Suspeito que Cao Guimarães, ao ter seu rosto diante do de Dominguinhos, não se vê nos olhos dele. Mas, antes de tudo, os atravessa, ao "invés de olhá-los no morno face a face das subjetividades significantes". Pois reconhece em seu personagem uma tentativa de "escapar ao rosto", por meio de "devires-animais", os quais fazem "com que os próprios traços de rostidade se subtraiam enfim à organização do rosto" (DELEUZE; GUATTARI, 1996, p. 36). Talvez tenha sido esse o encantamento do diretor de A alma do osso. Habitar, e se perder, no mundo possível de outrem, ser seu amigo, potencializar o falso de sua(s) existência(s), propor uma "dança a dois", experimentar sua rostidade, parecia mais sedutor ao olhar imaginário de Cao.

\section{A imagem do amigo}

Poucos minutos antes do término do filme, lê-se o seguinte texto na tela: "Dominguinhos da Pedra vive sozinho em cavernas há 41 anos na região de Itambé do Mato Dentro, MG. Recebe de aposentadoria um salário mínimo do governo". Depois disso, Dominguinhos mostra para o documentarista onde escondeu o canivete, que havia sido um presente da equipe, para, em caso de sua morte, a equipe pegá-lo de volta. Além disso, revela que guarda dólares. Nesse instante puxa o diretor pela mão, fazendo com que esta entre em quadro, seja rostificada, para tocar o saco plástico em que o dinheiro estava armazenado - sinal de resistência ou de amizade? Cao poderia buscá-lo quando Dominguinhos morresse.

O personagem diz: "Abaixo de Deus é o dinheiro, meu amigo. A pessoa sem dinheiro não é nada", meio a essa correspondência de afetos. Em troca Cao permite que seu amigo veja sua própria imagem pelo visor da câmera, enquanto outra registra esse momento e flagra a emoção de seu Dominguinhos pelo seu rosto, seus olhos. O eremita agora era uma imagem. Se seu próprio corpo não se desincrustaria dali, outro corpo - o de sua imagem - o faria por ele: percorreria o mundo.

Rafael de Almeida é doutorando no Programa de PósGraduação em Multimeios da Universidade Estadual de Campinas, onde desenvolve pesquisa sobre a obra de Cao Guimarães. 


\section{Referências}

AGAMBEN, Giorgio. O amigo. In: O que é o contemporâneo? e outros ensaios. Chapecó: Argos, 2009. p. 77-92.

The face. In: Means without end: notes on politics. University of Minnesota Press: Minneapolis, 2000. p. 91-100.

AUMONT, Jacques. O olho interminável: cinema e pintura. São Paulo: Cosac \& Naify, 2004.

COMOLLI, Jean-Louis. Ver e poder: a inocência perdida - cinema, televisão, ficção, documentário. Belo Horizonte: Editora UFMG, 2008.

DELEUZE, Gilles. A imagem-tempo. São Paulo: Brasiliense, 2007a.

Michel Tournier e o mundo sem outrem. In: Lógica do sentido. São Paulo: Perspectiva, 2007b. p. 311-330.

GUATTARI, Félix. Ano zero: rostidade. In: Mil platôs - capitalismo e esquizofrenia. vol. 3. Rio de Janeiro: Editora 34, 1996. p. 31-61.

EDUARDO, Cléber. Objetos sujeitos? In: Revista Cinética: cinema e crítica, Rio de Janeiro, maio 2008. Disponível em: <http://www.revistacinetica.com.br/docpersonagem.htm>. Acesso em: 16 mar. 2009.

ENTREVISTA exclusiva com o cineasta Cao Guimarães. In: Época, ed. 304, São Paulo, abril 2004. Disponível em: <http://revistaepoca.globo.com/Epoca/0,6993,EPT718586-1655,00.html>. Acesso em: 16 mar. 2009.

FOUCAULT, Michel. História da sexualidade I: a vontade de saber. Rio de Janeiro: Edições Graal, 1988.

GUIMARÃES, Cao. Breve nota sobre o eremita. Disponível em: <http://www.caoguimaraes.com/ page2/artigos/artigo_05.pdf>. Acesso em: 16 mar. 2009.

Documentário e subjetividade: uma rua de mão dupla. In: Sobre fazer documentários. São Paulo: Itaú Cultural, 2007. p. 68-73.

GUIMARÃES, César. Comum, ordinário, popular: figuras da alteridade no documentário brasileiro contemporâneo. In: MIGLIORIN, Cezar (Org.). Ensaios no real. Rio de Janeiro: Beco do Azougue, 2010. p. 181-197.

MACHADO, Arlindo. As linhas de força do vídeo brasileiro. In: Made in Brasil: três décadas de vídeo brasileiro. São Paulo: Iluminuras/ltaú Cultural, 2007. p. 15-47.

MIGLIORIN, Cezar. A superfície de um lago - bate-papo com Cao Guimarães. In: Revista Cinética: cinema e crítica, Rio de Janeiro, dez. 2006. Disponível em: <http://www.revistacinetica.com.br/ entrevistacaoguimaraes.htm>. Acesso em: 16 mar. 2009.

RANCIÈRE, Jacques. A partilha do sensível: estética e política. São Paulo: Editora 34, 2005.

SONTAG, Susan. A estética do silêncio. In: A vontade radical: estilos. São Paulo: Companhia das Letras, 1987. p. 11-40. 